\title{
Removal of Radioactive Cesium from Surface Soils Solidified Using Polyion Complex
}

\author{
-Rapid Communication for Decontamination Test \\ at Iitate-mura in Fukushima Prefecture-
}

\author{
Hirochika NAGANAWA ${ }^{1, *}$, Noriyuki KUMAZAWA ${ }^{2}$, Hiroshi SAITOH ${ }^{3}$, \\ Nobuyuki YANASE ${ }^{1}$, Hisayoshi MITAMURA ${ }^{1}$, Tetsushi NAGANO ${ }^{1}$, \\ Kaoru KASHIMA ${ }^{3}$, Tatsuya FUKUDA ${ }^{4,5}$, Zenko YOSHIDA ${ }^{1}$ \\ and Shun-ichi TANAKA ${ }^{5}$ \\ ${ }^{1}$ Nuclear Science and Engineering Directorate, Japan Atomic Energy Agency, 2-4 Shirane, Shirakata, Tokai-mura, Naka-gun, \\ Ibaraki 319-1195, Japan \\ ${ }^{2}$ Department of Biomolecular Functional Engineering, College of Engineering, Ibaraki University, 4-12-1 Nakanarusawa-cho, \\ Hitachi-shi, Ibaraki 316-8511, Japan \\ ${ }^{3}$ ATOX Co., Ltd., 161-2 Shirane, Muramatsu, Tokai-mura, Naka-gun, Ibaraki 319-1112, Japan \\ ${ }^{4}$ Chiyoda Technol Corporation, 1-7-12 Yushima, Bunkyo-ku, Tokyo 113-8681, Japan \\ ${ }^{5}$ NPO Radiation Safety Forum, Toranomonshiroyama Trust Tower (27F), Minato-ku, Tokyo 105-6027, Japan
}

\begin{abstract}
We tried the decontamination of surface soils for three types of agricultural land at Nagadoro district of Iitate-mura (village) in Fukushima Prefecture, which is highly contaminated by deposits of radionuclides from the plume released from the Fukushima Daiichi Nuclear Power Plant. The decontamination method consisted of the peeling of surface soils solidified using a polyion complex, which was formed from a salt solution of polycations and polyanions. Two types of polyion complex solution were applied to an upland field in a plastic greenhouse, a pasture, and a paddy field. The decontamination efficiency of the surface soils reached $90 \%$, and dust release was effectively suppressed during the removal of surface soils.
\end{abstract}

KEYWORDS: polyion complex, decontamination of surface soil, suppression of dust release, Iitate-mura, upland field in a plastic greenhouse, pasture, paddy field, radioactive cesium

\section{Introduction}

Because of the reactor meltdown and hydrogen explosion at the Fukushima Daiichi Nuclear Power Plant belonging to the Tokyo Electric Power Company Holdings, Inc. caused by the Great East Japan Earthquake that occurred on March 11, 2011, a large amount of radioactive material was released into the environment. In particular, a large amount of radioactive material was released from noon until $3 \mathrm{pm}$ on March 15, and this material was carried by the south-east

\footnotetext{
${ }^{*}$ Corresponding author, E-mail: naganawa.hirochika@jaea.go.jp

DOI : 10.15669 /fukushimainsights. Vol.4.22

(C) 2021 Atomic Energy Society of Japan. All rights reserved.

Originally published in Transactions of the Atomic Energy Society of Japan (ISSN 1347-2879), Vol. 10, No. 4, p.227-234

(2011) in Japanese. (Japanese version accepted: July 8, 2011)
} 
wind toward the north west of the nuclear power plant. Most of the radioactive materials are believed to have been precipitated in Namie-machi, Iitate-mura, and Kawamata-machi by rain and snow that fell from the evening until night on the same day ${ }^{1}$. Consequently, these highly contaminated areas were included in the planned evacuation areas because of concerns regarding accumulated doses exceeding $20 \mathrm{mSv}$ per year. For the residents to return to these evacuated areas and restart their lives, the radioactive material contaminating these areas must be removed.

In the present study, decontamination tests of sites including houses, farmlands, paddy fields, and pastures were selected as decontamination targets. We chose sites in the Nagadoro district, where the contamination was highest, particularly, Iitate-mura. The soil decontamination was tested via a series of decontamination tests using a method to remove surface soils solidified using a solid-state polyion complex (PIC) developed by Ibaraki University and Japan Atomic Energy Agency.

The decontamination method is based on the utilization of a PIC solid, which is uniformly dissolved in an aqueous solution by the addition of a salt, such as $\mathrm{KCl}$ or $\mathrm{NaCl}$. The salt can screen the electrostatic interactions between the polycations (positively charged polyions) and polyanions (negatively charged polyions), resulting in spontaneous precipitation of a PIC solid from the aqueous solution on the addition of water, which reduces the salt concentration. In the treatment process, an aqueous solution containing both polycations and polyanions is applied to the soil. The solution easily penetrates the soil to an appropriate depth. Then, a highly viscous PIC solid is formed by the runoff of the salt, solidifying the soil within the treated depth like an adhesive. The PIC solidified soil is stable for an extended period of time. In fact, PIC solids have a proven record: they were used after the Chernobyl Nuclear Power Plant Accident ${ }^{2)}$ to prevent the loss of radioactive materials as soil dust. Furthermore, experimental studies evaluating the applicability of PIC solids were carried out by Kumazawa et al. ${ }^{3,4}$. Methods using PIC solids have several advantages, for example, the ability to solidify the soil surface even with a comparatively small quantity of PIC (less than $2 \mathrm{wt} \%$ of soil), suppressing soil dust generation while solid removal work goes on, and easy post-processing of the solid material by gelation after the addition of water.

The features of this method and future subjects of investigation are described as rapid communication, together with the results of the decontamination experiments.

\section{Experimental}

\section{Reagents and Preparation of PIC Solutions}

(1) Reagents

(a) For a PIC solution of natural origin

Cationic cellulose ether chloride (hydroxyethylcellulose hydroxypropyltrimethylammonium chloride ether, HECHPTA, solid powder, $\mathrm{MW} \approx 50,000$, product name $\# \mathrm{QH} 200$ ) and anionic cellulose sodium salt (carboxymethyl cellulose sodium salt, CMC, solid powder, MW $\approx 750,000$, product number \#1350) were purchased from Daicel FineChem Ltd. and used without further purification.

(b) For a synthetic PIC solution

The cationic polyion poly (tetraalkyl ammonium) ion (polydiallyldimethyl ammonium chloride, PDADMAC, syrup-like state, $\mathrm{MW}=100,000-500,000$, product name \#Unisence FPA1001L) purchased from Senka Corporation and anionic polyacrylic acid (polyacrylic acid, PAA, solid powder, $\mathrm{MW} \approx 250,000$ ) purchased from Wako Pure 
Chemical Corporation were used without further purification.

(c) Salts

$\mathrm{KCl}$ and $\mathrm{NaOH}$ purchased from Wako Pure Chemical Corporation and $\mathrm{NaCl}$ purchased from The Salt Industry Center of Japan were used without further purification. Tap water was used without deionization and distillation.

\section{(2) Preparation of the PIC solutions}

(a) Preparation of the PIC solution of natural origin (200 L)

Approximately $100 \mathrm{~L}$ of water was placed in a $200 \mathrm{~L}$ tank. Then, $\mathrm{KCl}(4 \mathrm{~kg})$ or $\mathrm{NaCl}(4$ $\mathrm{kg}$ ) was added and dissolved in water by stirring using a power mixer (model PM-1011, Ryobi), yielding a salt solution. Meanwhile, HECHPTA (3 kg) and CMC (1 kg) were placed in another container and mixed well using a cooking spatula. Next, the solution was added to the above-mentioned tank containing the salt solution and mixed by stirring for $2 \mathrm{~h}$. Finally, the tank was filled with enough water to reach the full capacity of $200 \mathrm{~L}$ and stirred again, yielding the PIC solution.

(b) Preparation of synthetic PIC solution (200 L)

Approximately $100 \mathrm{~L}$ of water was placed in a $200 \mathrm{~L}$ tank. Then, $\mathrm{KCl}(10 \mathrm{~kg})$ and $\mathrm{NaOH}(0.48 \mathrm{~kg})$ were added and dissolved in water with stirring, yielding a salt solution. Then, PDADMAC (4.2 kg) was added to the tank containing the salt solution and stirred for about $1 \mathrm{~h}$ to facilitate complete dissolution. PAA $(0.87 \mathrm{~kg})$ was gradually added to the above-mentioned solution while stirring. PAA forms a rubber-like glob that is difficult to dissolve on mixing with water. Consequently, it required 2-3 days for the PAA to be dissolved completely. To speed up PAA dissolution, the undissolved glob was collected from the tank, transferred to a beaker, dissolved in the beaker, and returned to the tank. Finally, the tank was filled with water and stirred again to obtain $200 \mathrm{~L}$ of the synthetic PIC solution.

\section{Viscosity of the PIC Solution}

An SV-type viscosity meter (SV-10, A \& D Co., Ltd.) was used to measure the viscosity of the PIC solutions. The calibration was conducted using deionized water. The viscosity of the natural-origin PIC solution (approximately $150 \mathrm{mPa} \cdot \mathrm{s}$ ) is higher than that of the synthetic PIC solution (approximately $7 \mathrm{mPa} \cdot \mathrm{s}$ ), as shown in Table 1. Thus, the former seems to be suitable

Table 1 Viscosity of PIC solution applied and drying time for each zone

\begin{tabular}{|c|c|c|c|c|}
\hline Zone & & $\begin{array}{l}\text { PIC Solution } \\
\text { Sprayed }\end{array}$ & $\begin{array}{c}\text { Viscosity of } \\
\text { PIC Solution } \\
(\mathrm{mPa}-\mathrm{s})\end{array}$ & $\begin{array}{c}\text { Drying } \\
\text { Time }\end{array}$ \\
\hline \multirow{4}{*}{$\begin{array}{c}\text { Plastic } \\
\text { Greenhouse }\end{array}$} & Zone 1 & $\begin{array}{l}\text { Synthetic PIC } \\
\text { Solution }\end{array}$ & 6.72 & $4 \mathrm{~h}$ \\
\hline & Zone 2 & $\begin{array}{l}\text { Synthetic PIC } \\
\text { Solution }\end{array}$ & 6.72 & $4 \mathrm{~h}$ \\
\hline & Zone 3 & $\begin{array}{l}\text { Synthetic PIC } \\
\text { Solution }\end{array}$ & 6.72 & $6 \mathrm{~d}$ \\
\hline & Zone 4 & $\begin{array}{l}\text { Natural PIC }(\mathrm{KCl}) \\
\text { Solution }\end{array}$ & 152 & $6 \mathrm{~d}$ \\
\hline \multirow{2}{*}{ Pasture } & Zone 5 & $\begin{array}{l}\text { Natural PIC }(\mathrm{KCl}) \\
\text { Solution }\end{array}$ & 152 & $6 \mathrm{~d}$ \\
\hline & Zone 6 & $\begin{array}{l}\text { Natural PIC }(\mathrm{NaCl}) \\
\text { Solution }\end{array}$ & 149 & $6 \mathrm{~d}$ \\
\hline Paddy & Zone 7 & $\begin{array}{l}\text { Natural PIC }(\mathrm{KCl}) \\
\text { Solution }\end{array}$ & 152 & $6 \mathrm{~d}$ \\
\hline
\end{tabular}


for the treatment of sandy soil and soft field soil, which aqueous solutions easily penetrate, and the latter seems to be suitable for well-trodden soil such as the front yards of private houses and the soil of dried paddy fields where the aqueous solution poorly penetrates because of its relatively high density.

\section{Target Soils for Decontamination}

\section{(1) Location of decontamination area and contaminating nuclides}

The Nagadoro district in Iitate-mura where the decontamination test was conducted is located at $37.6127^{\circ} \mathrm{N} 140.7493^{\circ} \mathrm{E}$. The major nuclides contaminating this area on May 19, 2011, just before the experiment was conducted, were ${ }^{137} \mathrm{Cs}$ (half-life 30 years) and ${ }^{134} \mathrm{Cs}$ (half-life 2 years) ${ }^{5)}$.

\section{(2) Types of PIC solutions for different land uses}

(a) Vegetable fields under plastic greenhouses

An area of $4 \mathrm{~m} \times 10 \mathrm{~m}$ under a plastic greenhouse $(5.3 \mathrm{~m} \times 44.5 \mathrm{~m})$ was adopted for a decontamination test (Figure 1).

The decontamination area was further divided into small zones. The synthetic PIC solution was sprayed onto zones $1-3$, and the natural-origin PIC $(\mathrm{KCl})$ solution was sprayed onto zone 4 (11 am to $0 \mathrm{pm}$, May 20) (see Figure 1 and Table 1). The volume of the PIC solution sprayed was about $5 \mathrm{~L} / \mathrm{m}^{2}$. To apply the synthetic PIC solution, which had a low viscosity, a commercially available gardening watering can with a shower

(1)

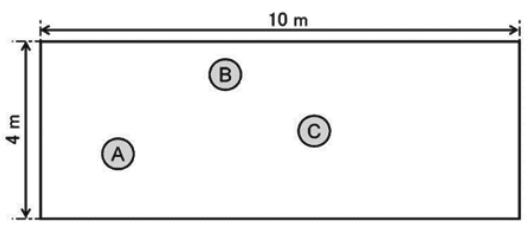

(2)

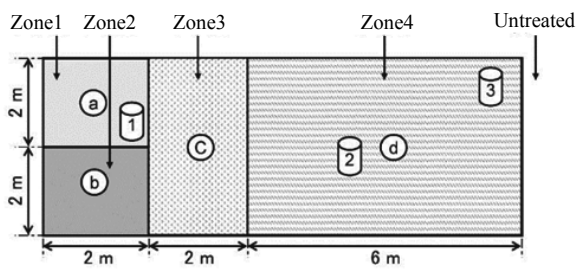

Figure 1 Layout of the decontamination area in a vinyl greenhouse before and after zoning

(1) Before zoning and (2) After zoning

Zone 1: Synthetic PIC solution sprayed and dried 4 hours and then $1-2 \mathrm{~cm}$ soil surface removed

Zone 2: Synthetic PIC solution sprayed and dried 4 hours and then $4-5 \mathrm{~cm}$ soil surface removed

Zone 3: Synthetic PIC solution sprayed and dried 6 days and then 3-4 cm soil surface removed

Zone4: Natural-origin PIC $(\mathrm{KCl})$ solution sprayed and dried 6 days and then 3-4 $\mathrm{cm}$ soil surface removed

A-C: Radioactivity measuring point (before spraying PIC solution)

a-d: $\quad$ Radioactivity measuring point (after spraying PIC solution and drying and then removing soil surface)

1-3: $\quad$ Sampling points for core samples 
head was used. To apply the natural-origin PIC solution, which had a high viscosity, the watering can was used with the shower head removed.

(b) Pasture

A decontamination area of $5 \mathrm{~m} \times 5 \mathrm{~m}$ of pasture was divided into small zones (Figure 2). A natural-origin PIC $(\mathrm{KCl})$ solution was sprayed onto zone 5, and the other natural-origin PIC $(\mathrm{NaCl}$ ) solution was sprayed in zone 6 (at 2 pm, May 20) (see Figure 2 and Table 1). The PIC solutions were sprayed with the same volume as that mentioned above and treated in a similar manner.

(c) Paddy fields

An area of $5 \mathrm{~m} \times 5 \mathrm{~m}$ of a paddy field was decontaminated (Figure 3). The natural-origin

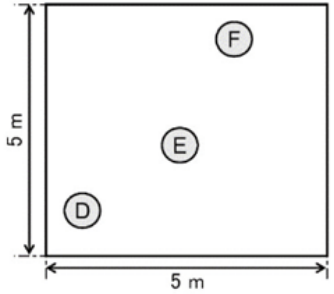

(1)

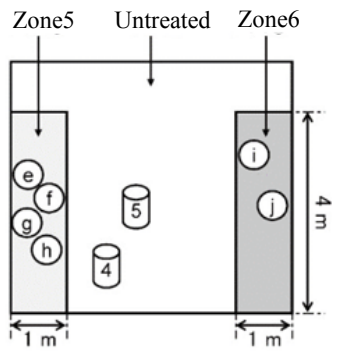

(2)

Figure 2 Layout of decontamination area in pasture

(1) Before zoning and (2) After zoning

Zone 5: Natural-origin PIC $(\mathrm{KCl})$ solution sprayed and dried 6 days and then 2-4 cm soil surface removed

Zone 6: Natural-origin PIC $(\mathrm{NaCl})$ solution sprayed and dried 6 days and then 2-4 cm soil surface removed

D-F: Radioactivity measuring point (before spraying PIC solution)

e-j: $\quad$ Radioactivity measuring point (after spraying PIC solution and drying and then removing soil surface)

4-5: $\quad$ Sampling points for core samples

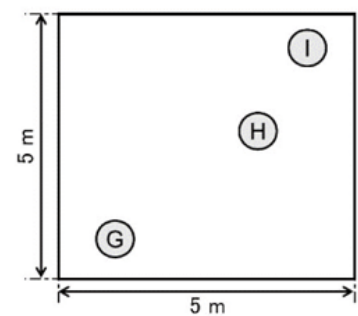

(1)

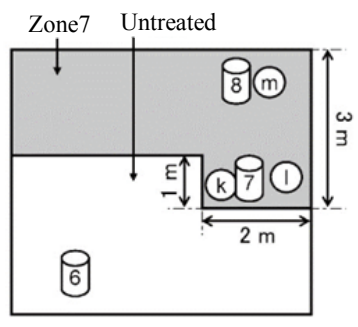

(2)

Figure 3 Layout of decontamination area in a paddy field

(1) Before zoning and (2) After zoning

Zone 7: Natural-origin PIC $(\mathrm{KCl})$ solution sprayed and dried 6 days and then 2-10 cm soil surface removed

G-I: $\quad$ Radioactivity measuring point (before spraying PIC solution)

$\mathrm{k}-\mathrm{m}$ : $\quad$ Radioactivity measuring point (after spraying PIC solution and drying and then removing soil surface)

6-8: $\quad$ Sampling points for core samples 
PIC ( $\mathrm{KCl}$ ) solution was sprayed in zone 7 (at $1 \mathrm{pm}$, May 20) (see Figure 3 and Table 1). The PIC solution was sprayed with the same volume as that mentioned above and treated in a similar manner.

\section{(3) Method for soil surface removal and drying time}

After applying the PIC solution to the surface of the soil for decontamination, the PIC was left for 4 or $6 \mathrm{~h}$ for solidification (see Table 1), and, subsequently, the soil surface layer of a specified depth was removed using a farm hoe.

The weather during the period from May 20 (the day when PIC solutions were applied) to May 26 (the day when the soil layer was removed) was as follows ("Past Weather Data" provided by Japan Meteorological Agency) ${ }^{6}$. 5/20: Fine, later cloudy, precipitation $0 \mathrm{~mm}$, and 6.5-29. ${ }^{\circ} \mathrm{C}$; $5 / 21$ : fine, $0 \mathrm{~mm}$, and $9.8-28.5^{\circ} \mathrm{C} ; 5 / 22$ : cloudy, later rainy, $2.5 \mathrm{~mm}, 7.5-22.1^{\circ} \mathrm{C}$; 5/23: cloudy, $0 \mathrm{~mm}, 4.2-17.1^{\circ} \mathrm{C} ; 5 / 24$ : cloudy, later fine, $0 \mathrm{~mm}, 5.7-18.2^{\circ} \mathrm{C} ; 5 / 25$ : fine, $0 \mathrm{~mm}$, 5.3-25. $3^{\circ} \mathrm{C}$; and $5 / 26$ : fine, later cloudy, $0 \mathrm{~mm}, 8.6-19.4^{\circ} \mathrm{C}$.

(a) Vegetable fields under plastic greenhouses

Concerning zones 1 and 2 in Figure 1, the removal of the soil surface layer was conducted $4 \mathrm{~h}$ after the application of the synthetic PIC solution. In zone 1, a soil surface layer of 1-2 cm was removed, and, in zone 2, a soil surface layer of 4-5 cm was removed. However, the aqueous PIC solutions had not sufficiently solidified. During the removal of the wet mixture of soil and PIC from the soil surface, the generation of soil dust was not observed.

On the other hand, in zone 3 in Figure 1 where the synthetic PIC solution had been sprayed and in zone 4 where the natural-origin PIC solution had been sprayed, soil surface layers of 3-4 cm were removed 6 days after the application of the PIC solutions (11 am, May 20 until 10 am, May 26).

(b) Pastures

The soil surface layers of specified depths were removed in zones 5 and 6 in Figure 2 after leaving these zones for 6 days after the application of the PIC solutions (at 2 pm, May 20 until 3pm, May 26).

(c) Paddy fields

The soil surface layer of a specified depth was removed in zone 7, as shown in Figure 3 , after leaving this zone for 6 days after the PIC solution had been applied ( $1 \mathrm{pm}$, May 20 until 2 pm, May 26).

\section{Measurement of Radioactive Cesium Contamination of the Soil Surface}

\section{(1) Measuring instrument}

A Geiger-Müller (GM) survey meter (TGS-133, Aloka) was used for measuring the $\beta$-ray count rate on site.

\section{(2) Measurement conditions}

The $\beta$-ray count rate of the soil surface was measured with a fixed time constant at $10 \mathrm{~s}$ using the GM survey meter TGS-133. Furthermore, to prevent the GM probe from becoming contaminated, the soil surface at the measurement points was covered with a polyethylene sheet $0.1 \mathrm{~mm}$ thick $\times 40 \mathrm{~cm}$ long $\times 20 \mathrm{~cm}$ wide and the GM probe was covered by a polyethylene sheet $0.05 \mathrm{~mm}$ thick and placed in close contact with the soil surface for the measurements. The $\beta$-ray count rate of the soil surface before decontamination was measured on May 20, and the soil surface measurement after decontamination was conducted on the day of soil removal. 


\section{(3) Measurement accuracy (uncertainty)}

The background was not corrected for the measurements of $\beta$-ray count rate on site because the whole area was contaminated in Nagadoro district and Iitate-mura. The standard deviation $(\sigma)$ of the $\beta$-ray count rate $(n)$ was obtained using the following equation considering time constant $\tau^{7)}$ :

$$
\sigma=n /(2 n \tau)^{1 / 2}
$$

Furthermore, when obtaining the average of the $\beta$-ray count rate in the same zone, the dispersion depending on the different measuring points was considered to be the error.

\section{(4) Definition of the decontamination rate}

The decontamination rate $(D)$ as a percentage $(\%)$ was obtained by using the $\beta$-ray count rate of the soil surface before decontamination $\left(n_{\mathrm{i}}\right)$ and that after decontamination $\left(n_{\mathrm{f}}\right)$ :

$$
D=\left\{\left(n_{\mathrm{i}}-n_{\mathrm{f}}\right) / n_{\mathrm{i}}\right\} \times 100
$$

\section{Measurement of $\gamma$-Ray Air Dose Rate}

To measure the $\gamma$-ray air dose rate at the site, a $\mathrm{NaI}(\mathrm{Tl})$ scintillation survey meter (TCS-161, Aloka, calibration constant 1.0) was used. The $\gamma$-ray air dose rate was measured at heights of 0 and $1 \mathrm{~m}$ while holding the scintillation probe horizontally and with a time constant of $10 \mathrm{~s}$. In addition, the scintillation probe was covered with a polyethylene sheet $0.05 \mathrm{~mm}$ thick to prevent the scintillation probe from becoming contaminated. Furthermore, for measurement at a height of $0 \mathrm{~m}$, the soil surface at the measuring points was covered by a polyethylene sheet $0.1 \mathrm{~mm}$ thick $\times 40 \mathrm{~cm}$ long $\times 20 \mathrm{~cm}$ wide, and the scintillation probe was placed on the sheet for measurement. The measurement was conducted on May 20 before decontamination, and the measurement after decontamination was conducted only at the points where soil removal was conducted on the same day.

\section{Measurement of the Depth Distribution of Radioactive Cesium}

\section{(1) Sampling and treatment of soil core samples}

Soil core samples $2.5 \mathrm{~cm}$ diameter were collected. A portion $0-5 \mathrm{~cm}$ depth and $1 \mathrm{~cm}$ thickness was cut on site and the deeper portion was placed whole into two polyethylene bags $0.04 \mathrm{~mm}$ thickness (with zippers) and taken to the laboratory for analysis.

(a) Vegetable fields under plastic greenhouses

Soil core samples 15-cm depth were collected at three points (1-3) shown in Figure 1.

(b) Pastures

Soil core samples were collected at two points (4 and 5) as shown in Figure 2. Because the pasture soil was too hard to obtain long soil core samples, samples $7 \mathrm{~cm}$ depth at point 4 and $4 \mathrm{~cm}$ depth at point 5 were collected.

(c) Paddy fields

Soil core samples were collected at three points (6-8) as shown in Figure 3. To avoid the influence of the crop stubble, where the cesium contamination is concentrated, samples were collected at points located between stubble. 


\section{(2) Measurement of radioactivity concentration of cesium}

The $\beta$-ray count rate of core samples was measured using a GM survey meter (model TGS133 and TG-136, Aloka) in the laboratory, and the depth distribution of the cesium radioactivity concentration in the soil was obtained from the above-mentioned measurements. The background values of the $\beta$-ray count rate were obtained $(50-60 \mathrm{cpm})$ in the laboratory, and these values were used to compensate for the background. A model TGS-133 meter was used with a conversion factor $4.3 \times 10^{-2} \mathrm{~Bq} / \mathrm{cpm}$ and a time constant of $30 \mathrm{~s}$ for measuring the core samples taken from the surface to a depth of $5 \mathrm{~cm}$. A model TGS-136 with a conversion factor $4.6 \times 10^{-2}$ $\mathrm{Bq} / \mathrm{cpm}$ operating in scaler mode was used for 1 min to measure the core samples taken from a depth greater than $5 \mathrm{~cm}$. In this $\beta$-ray count-rate measurement, we carefully sealed the soil samples in a polyethylene bag during measurement to maintain the wet condition. In addition, soil samples weighing more than $10 \mathrm{~g}$ obtained from a depth greater than $5 \mathrm{~cm}$ were cut into samples weighing less than $5 \mathrm{~g}$ and were measured in a similar manner using a double polyethylene bag $0.04 \mathrm{~mm}$ thickness (with a zipper). Furthermore, in the measurements, the samples were distributed as widely as possible within the range of the $5 \mathrm{~cm}$ diameter detection window of the GM probe, and the GM probe covered with a $0.05 \mathrm{~mm}$ thickness polyethylene sheet was pressed against the polyethylene bag. The weight of the soil samples was determined using an electronic scale. The radioactive concentration of soil samples was obtained by multiplying the $\beta$-ray count rate by each conversion factor mentioned above and then by dividing the product by the weight of the samples.

\section{Measurement of Floating Dust Concentration}

\section{(1) Dust collectors}

A portable air sampler (model L100, Munro Group Ltd.) was used for collecting floating dust.

Filter paper (\#HE-40TA, Advantec) having an outer diameter of $60 \mathrm{~mm}$ was used as the filter to collect floating dust. To increase the generation of floating dust, a household electric fan (MF-P30C, U-Ing) was used as a blower. The wind speed of the fan was measured in advance in the laboratory using a sensitive anemometer (ISA-80, Sibata Scientific Technology).

\section{(2) Measurement of radioactive cesium in floating dust}

The measurement of the floating dust concentration in air was conducted to determine the suppression of dust generation after the solidification of the soil surface layer with PIC in the vegetable fields under plastic greenhouses at the following three points (refer to Figure 1 for zone numbers): (1) Untreated points where no PIC solution had been sprayed, i.e., outside the decontamination area, (2) points in zone 4 where the natural-origin PIC solution had been sprayed, and (3) points in zone 3 where the synthetic PIC solution had been sprayed.

The equipment configuration used in the experiment is shown in Figure 4. The electric fan for blowing and the air sampler for collecting floating dust were $2 \mathrm{~m}$ from each other on the soil surface. The direction of the electric fan (having a height above ground level at its center of $33 \mathrm{~cm}$ ) was adjusted in such a way that the center of the air flow hit the filter of the floating dust collector (the height of its center was approximately $10 \mathrm{~cm}$ above ground level), and a high wind strength mode was selected to obtain a wind speed of $1.9 \mathrm{~m} / \mathrm{s}(10 \mathrm{~cm}$ above ground level) at the midpoint.

(a) Before removing the soil surface

The floating dust collector was operated immediately after blowing started, and the 


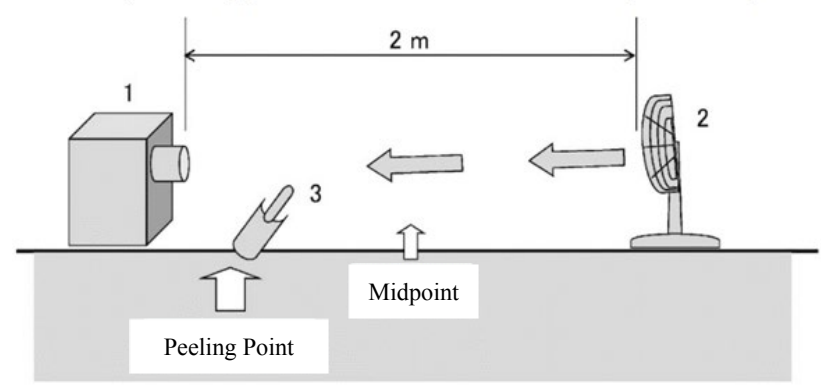

Figure 4 Equipment configuration used for collecting the floating dust 1: Floating dust collector, 2: electric fan (household), and 3: scoop for removing the soil surface

floating dust was collected in the filter for $5 \mathrm{~min}$ at a wind speed of $100 \mathrm{~L} / \mathrm{min}^{-1}$. The filter samples after dust collection were put into double polyethylene bags $0.04 \mathrm{~mm}$ thickness (with a zipper) and taken to the laboratory for analysis.

(b) In the course of soil surface removal

An electric fan was used to simulate wind flow over the soil surface during soil removal. The experiment was repeated 10 times (approximately 1 min was required for the removal of each sample) at the soil removal point shown in Figure 4 (in an area of $30 \mathrm{~cm} \times 30 \mathrm{~cm}$ approximately $10 \mathrm{~cm}$ away from the filter of the dust collector) using a gardening scoop. The floating dust generated during the operation was collected on the filter. Similarly, the filter samples after the dust collection operation were put into double polyethylene bags (each $0.04 \mathrm{~mm}$ thickness) with zippers and taken to the laboratory for analysis.

\section{(3) Measurement of filter radioactivity}

The $\beta$-ray count rate of the filter samples was measured using a GM survey meter (model TGS-136, Aloka) in the laboratory. The measurement was conducted using a TGS-136 (conversion factor $4.6 \times 10^{-2} \mathrm{~Bq} / \mathrm{cpm}$, operating in scaler mode to take measurements over $10 \mathrm{~min}$ ) with the GM probe covered by a polyethylene sheet $0.05 \mathrm{~mm}$ thickness. The probe was pressed against the polyethylene bag containing the filter sample. We took care to set the detection window of the GM probe, which had a diameter of $5 \mathrm{~cm}$, in such a way that the window covered the entire the floating dust collection area of the filter. The radioactive cesium concentration of the floating dust was obtained by multiplying the $\beta$-ray count rate by a conversion factor and dividing the product by the quantity of air collected.

\section{Results and Discussion}

\section{Soil Contamination of the Experimental Targets}

(1) Overview of land use (conditions of the soil surface, plants, etc.)

(a) Overview of vegetable fields under plastic greenhouses

By March 15, the vegetable fields under the plastic greenhouses had not been harvested for several months, and the vinyl sheets had been removed, leaving the fields open. For this reason, the contamination by rainfall on March 15 was almost the same as that in other fields used for agricultural purposes near the greenhouses. After March 15, no 
agricultural work was carried out. The land surface was dry on May 20 with neither agglomeration nor weeds; thus, the soil surface was easily scraped away with a scoop.

(b) Overview of pasture

The pastures targeted for decontamination were covered with grasses over the winter that had been mowed the previous autumn. By March 15, when the radioactive contamination occurred, some plants had begun to germinate. Based on visual observation on May 20, the land surface was covered with flat hay and cattle dung fertilizer, and pastures and weeds were sprouting through them. Based on the in situ measurement of the $\beta$-ray count rate using a GM survey meter, the radioactive cesium was concentrated in the roots of the dried hay.

(c) Overview of paddy fields

The paddy fields targeted for decontamination were contaminated on March 15; the rice had been harvested the previous autumn and the fields had then been left untouched. The soil surface was almost dry by May 20 and cracked in some spots. The withered stems and roots (stubble) after the crop of rice were observed remained intact. The in situ radioactivity measurements revealed that the radioactivity was concentrated in the stubble, and almost no radioactivity was observed on the bottom soil surface after pulling out the stubble. Consequently, it was found that removing this stubble was an effective way of decontaminating the paddy fields.

(2) $\gamma$-Ray air dose rate in each land-use classification and depth distribution of radioactive cesium

(a) Vegetable fields under plastic greenhouse

The $\gamma$-ray air dose rate at point $\mathrm{C}$ in Figure 1 was $19 \mu \mathrm{Sv} / \mathrm{h}$ at a height of $0 \mathrm{~m}$ and $12 \mu \mathrm{Sv} / \mathrm{h}$ at a height of $1 \mathrm{~m}$ (Table 2).

The depth distribution of radioactive cesium in the soil obtained from the measurement of core samples is shown in Figure 5. As a result of fitting with an exponential function, assuming a concentration of naturally derived $\beta$-nuclides in soil of $0.46 \mathrm{~Bq} / \mathrm{g}$ and because a net $\beta$-ray count rate of $10 \mathrm{cpm} / \mathrm{g}$ in soil deeper than $5 \mathrm{~cm}$ of the core sample was detected, we found that $99 \%$ of radioactive cesium was present to a depth of $5 \mathrm{~cm}$ from the surface, and the radioactivity did not penetrate deeper than $7 \mathrm{~cm}$.

(b) Pasture

The $\gamma$-ray air dose rates at points D, E, and F in Figure 2 were $20-21 \mu \mathrm{Sv} / \mathrm{h}$ at a height of $0 \mathrm{~m}$ and $12-13 \mu \mathrm{Sv} / \mathrm{h}$ at a height of $1 \mathrm{~m}$ (Table 2).

The depth distribution of radioactive cesium in soil obtained from the core sample measurement is shown in Figure 6. Compared to the results for vegetable fields under plastic greenhouses shown in Figure 5, the radioactive cesium in the pasture was found to be concentrated in a shallower region, and more than $99 \%$ of the radioactive cesium remained about $3 \mathrm{~cm}$ from the surface.

(c) Paddy fields

The $\gamma$-ray air dose rates at points G, H, and I in Figure 3 were $15 \mu \mathrm{Sv} / \mathrm{h}$ at a height of $0 \mathrm{~m}$ and $10 \mu \mathrm{Sv} / \mathrm{h}$ at a height of $1 \mathrm{~m}$ (Table 2).

The depth distribution of radioactive cesium in the soil obtained from the measurements of the core samples is shown in Figure 7. Using a similar fitting as described above, we found that more than $99 \%$ of the radioactive cesium remained as deep as $3 \mathrm{~cm}$ from the soil surface. It was also found that the depth distribution of radioactive cesium in paddy field soil was analogous to that of the pasture soil, and the radioactive cesium was distributed nearer to the surface compared to that of the soil for the vegetable fields 
Table 2 Measurements of radioactivity at the points targeted for decontamination.

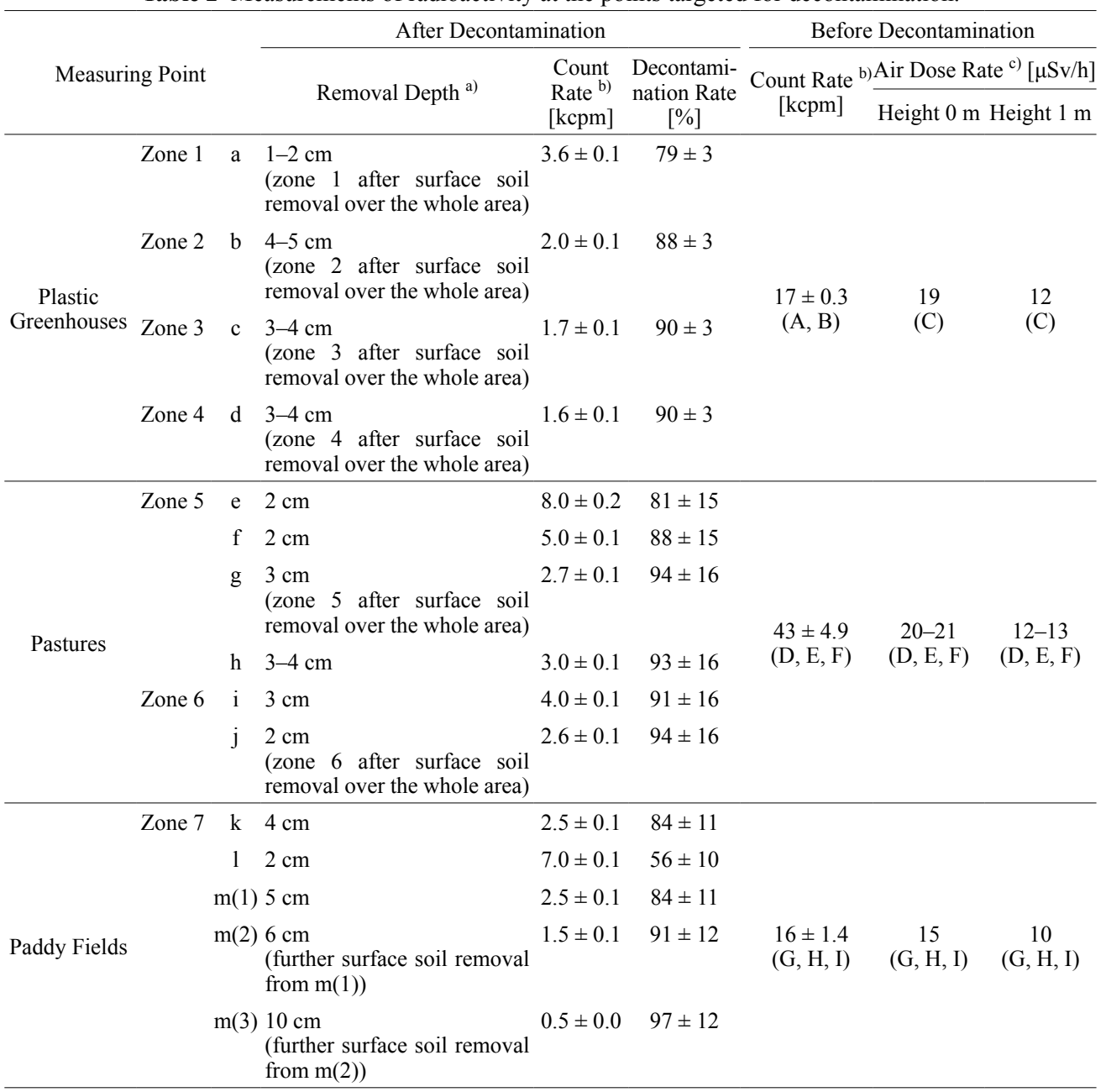

a) Surface soil removal after $4 \mathrm{~h}$ at points a and $\mathrm{b}$ and after $6 \mathrm{~d}$ at other points

b) Measurement of $\beta$-ray using a GM survey meter (including the background)

c) Measurement of $\gamma$-ray using a NaI scintillation survey meter

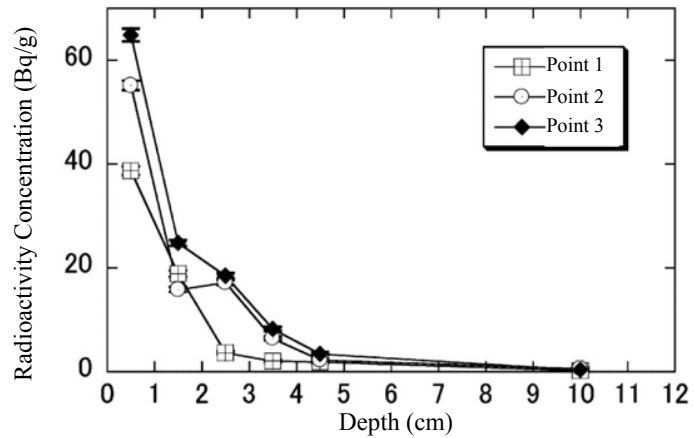

Figure 5 Depth distribution of radioactive cesium in the soil in vegetable fields under plastic greenhouses obtained by core sampling 


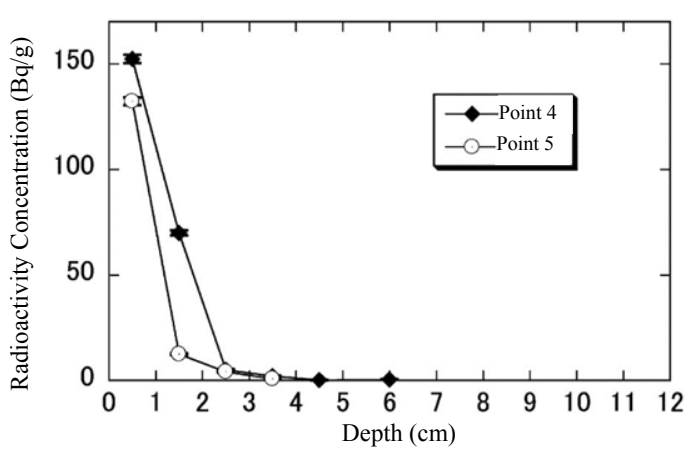

Figure 6 Depth distribution of radioactive cesium in the soil in pasture obtained by core sampling

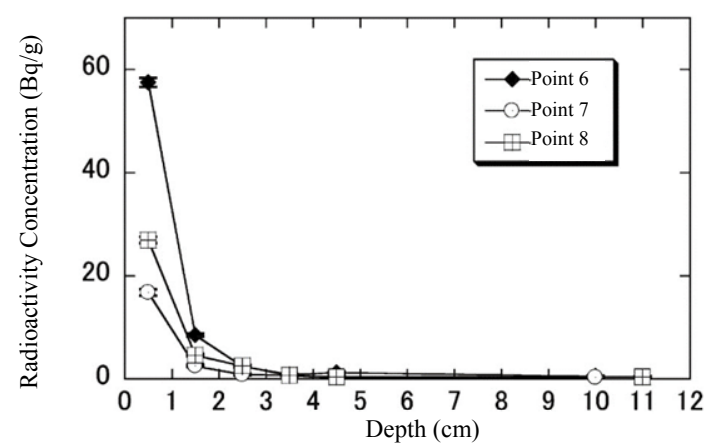

Figure 7 Depth distribution of radioactive cesium in the soil in paddy fields obtained by core sampling

under plastic greenhouses. The reason for this is assumed to be the lower penetration of rainfall in paddy fields and pastures than in the vegetable fields under the plastic greenhouses where the soil contained more voids.

\section{Decontamination Effect of the Removing the Soil Surface}

\section{(1) Vegetable fields in plastic greenhouses}

The $\beta$-ray count rates of the soil surface before decontamination at points A and B in Figure 1 are shown in Table 2 . The $\beta$-ray count rate on the soil surface before decontamination was almost uniform within the targeted decontamination range, and the average was $17 \mathrm{kcpm}$.

The $\beta$-ray count rates of the soil surface at points a-d shown in Figure 1 are summarized in Table 2. The removal of the soil surface $4 \mathrm{~h}$ after the PIC solution had been applied and penetrated the soil to a depth of 1-2 cm from the surface in zone 1 resulted in a decontamination rate of approximately $80 \%$ at point a. The removal of the soil surface in zone 2 after similar spraying and penetration to a depth of 4-5 $\mathrm{cm}$ from the soil surface resulted in a decontamination rate of about $90 \%$ at point $b$ (Table 2). The $\gamma$-ray air dose rates at point a and point $b$ after decontamination decreased respectively to 6.5 and $4.0 \mu \mathrm{Sv} / \mathrm{h}$ at a height of $0 \mathrm{~m}$ and 10.6 and $9.7 \mu \mathrm{Sv} / \mathrm{h}$ at a height of $1 \mathrm{~m}$.

The natural-origin PIC sprayed in zone 4 was fixed to a sufficient hardness after 6 days and could be removed as soil flakes having a thickness of $0.5-1 \mathrm{~cm}$ and a size ranging from that of a 
100 yen coin to the size of the palm of the hand by using a gardening scoop, as shown in Photo 1. By measuring the $\beta$-ray count rate of the soil surface after the removal of these soil flakes, a decontamination rate of $72-82 \%$ was obtained. In the actual decontamination operation, 3-4 $\mathrm{cm}$ of the soil surface layer was removed. As a result, a decontamination rate of $90 \%$ was obtained at points $\mathrm{c}$ and $\mathrm{d}$ by removing $3-4 \mathrm{~cm}$ of soil surface layer solidified by PIC for both zone 3 (solidified with synthetic PIC solution) and zone 4 (solidified with natural-origin PIC solution) (Table 2).

\section{(2) Pasture}

The results of the measurement of the $\beta$-ray count rate of the soil surface before decontamination at points D-F in Figure 2 are shown in Table 2. The average $\beta$-ray count rate of the pasture soil surface before decontamination was $43 \mathrm{kcpm}$, which is $2-3$ times higher than that on the soil surfaces of the vegetable fields under plastic greenhouses or the paddy fields targeted for the present decontamination test.

The natural-origin PIC sprayed on soil surface solidified to a sufficient hardness. The grasses growing in the pasture set their roots within a shallow range (range of depth about $2-3 \mathrm{~cm}$ ) from the soil surface; therefore, the soil and the solidified PIC were able to be removed uniformly together with grasses using a gardening scoop. A decontamination rate of $94 \%$ was obtained at both points $\mathrm{g}$ and $\mathrm{j}$ (removing 3 and $2 \mathrm{~cm}$ depth of soil, respectively) (Table 2).

\section{(3) Paddy fields}

The results of the measurements of the $\beta$-ray count rate of the soil surface before decontamination at points $\mathrm{G}-\mathrm{I}$ in Figure 3 are listed in Table 2 . The average $\beta$-ray count rate for paddy field soil surfaces before contamination was $16 \mathrm{kcpm}$.

The natural-origin PIC sprayed in paddy fields solidified to a sufficient hardness. The measured $\beta$-ray count rates of the soil surface after removing $2-10 \mathrm{~cm}$ of the soil surface layer at points $\mathrm{k}-\mathrm{m}$ shown in Figure 3 are summarized in Table 2. As a result, decontamination rates of $56 \%$ (removing a thickness of $2 \mathrm{~cm}$ ), 84\% (removing a thickness of $4 \mathrm{~cm}$ ), $84 \%$ (removing a thickness of $5 \mathrm{~cm}$ ), $91 \%$ (removing a thickness of $6 \mathrm{~cm}$ ), and 97\% (removing a thickness of 10 $\mathrm{cm}$ ) were obtained. These results would appear to indicate that the higher decontamination rate was obtained by removing a deeper soil level. However, because about $99 \%$ of the radioactive cesium is presumed to be removed by removing $3 \mathrm{~cm}$ of soil, based on the depth distribution of radioactive cesium obtained by measuring soil core samples, the decontamination rate listed

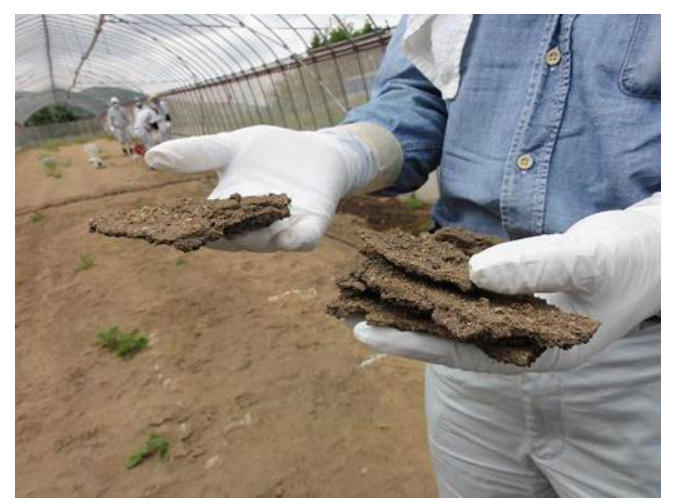

Photo 1 Soil flakes of the vegetable fields under plastic greenhouses solidified by natural-origin PIC 
in Table 2 would be even higher if in situ background compensation of measurements were possible.

\section{Suppression of Dust Generation}

\section{(1) Effect of PIC before surface soil removal}

The quantity of radioactive cesium in the captured floating dust was determined, and the results are shown in Figure 8 (1) as the radioactivity of the captured air. The quantity of airborne radioactive cesium produced from the soil surface captured by the solidified PIC solution is lower than that of the soil surface without solidification treatment, especially after solidification using the natural-origin PIC solution, that is, 0.36 times lower.

\section{(2) Effect of PIC during surface soil removal}

The quantity of radioactive cesium in the captured floating dust was obtained as above, and the results are shown in Figure 8 (2) as the radioactivity of the captured air. The quantity of airborne radioactive cesium produced during surface soil removal was reduced by the solidification treatment using the PIC solution, especially using natural-origin PIC solution. The radioactive cesium produced was 0.32 times smaller than the case without any soil surface treatment. For context, the radioactivity concentration in the captured air during surface soil removal operation was larger by one order of magnitude than that before operation.

\section{Application of PIC to Other Materials for Decontamination}

The decontamination of more complex environments, such as the surroundings of a house, is required; thus, the use of the PIC solution was tested for surface soil removal from the garden, the removal of solid material accumulated in the roof gutters, and the removal of withered Cryptomeria branches.

The soil of the gardens had been trodden down and compacted by vehicles, which made it difficult for the PIC solution to penetrate the soil. In particular, the natural-origin PIC solution did not penetrate the soil to a sufficient depth. For this reason, the soil must be treated (e.g., by pricking) after spraying in the case of using the natural-origin PIC solution.
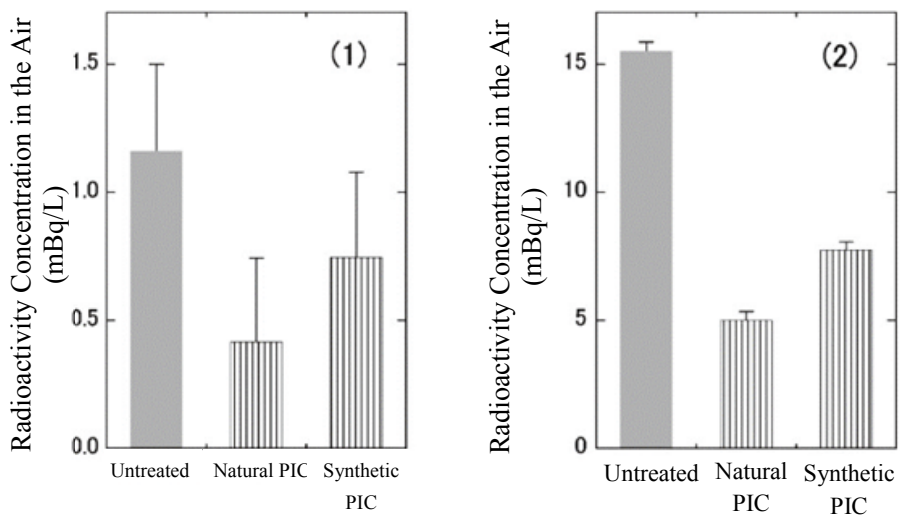

Figure 8 Suppression of floating dust generation using PIC solidification

(1) Quantity of airborne radioactive cesium before soil surface removal

(2) Quantity of airborne radioactive cesium during soil surface removal 
The amount of floating dust was reduced successfully after the advanced spraying of the PIC solution during various operations. The proper treatment of the waste collected during the decontamination operation is currently under investigation and further tests will be required. At that time, the use of the PIC solution for inhibiting dust generation from waste was considered to be effective.

\section{Summary}

We confirmed that the solidification of the soil surface layer using a polyion complex (PIC), followed by removal of the soil, is effective for the decontamination of soil contaminated by radioactive cesium. The decontamination rate of the soil surface layer of vegetable fields under plastic greenhouses, pastures, and paddy fields was higher than $90 \%$. Furthermore, the production of airborne radioactive cesium concentrated in the soil surface layer and scattered by the wind was effectively suppressed. From the experimental data, especially in the vegetable fields under plastic greenhouses, the method using high viscosity natural-origin PIC solution was particularly effective.

It is expected that the range of application of this method will be expanded in the future by the development of PICs having suitable properties for application to different types of soil.

\section{References}

1) M. Chino, H. Nakayama, H. Nagai et al., "Preliminary estimation of release amounts of ${ }^{131} \mathrm{I}$ and ${ }^{137} \mathrm{Cs}$ accidentally discharged from the Fukushima Daiichi nuclear power plant into the atmosphere," J. Nucl. Sci. Technol., 48(7), 1129-1134(2011).

2) A. B. Zezin, N. Kumazawa "Chemical Treatment of Chernobyl Nuclear Power Plant - How did the Russian Chemists do for Prevention of Expanded Radioactivity Contamination," Chem. Today, 339, 30-38(1999). [in Japanese]

3) N. Kumazawa, T. Ozawa, V. G. Sergeyev et al., "The Application of Chemical Treatment Used in Chernobyl Accident to Tokai-mura," Annual Report of the Institute of Regional Studies Ibaraki University Sup. Vol. The Tokai-mura Criticality Accident and Regional Society 69-75(2002). [in Japanese]

4) N. Kumazawa, T. Ozawa, V. G. Sergeyev et al., "Development of Soil Solidification Method using Natural Polyion - Aiming at Improvement of Treatment Method in Chernobyl Accident," Annual Report of the institute of Regional Studies Ibaraki University Sup. Vol. Tokai-mura Nuclear Anti-Disaster Measures and Regional Society 7-11(2005). [in Japanese]

5) MEXT, Dust Sampling around Fukushima Daiichi and Daini Nuclear Power Plants, Measurement Results of Environmental Specimens and Soil Monitoring: The measurements on soil monitoring (as of 10:00, Jun. 03, 2011), http://www.mext.go.jp (2011). [in Japanese]

6) JMA, Weather Statistical Information "Past Weather Data Search," (http://www.jma.go.jp/jma/index. html) (2011). [in Japanese]

7) G. F. Knoll (author), Itsuro Kimura, Eiji Sakai (translator), Radiation Measuring Handbook (Vol. 3), Nikkan Kogyo Shimbun, 708-711(2001). [in Japanese] 